\title{
Intergeracionalidade no Contexto das Práticas Educativas \\ de Mães de Crianças Pré-Escolares
}

\author{
Daniele Dalla Porta ${ }^{1}$ \\ 'Universidade Federal de Santa Maria, RS, Brasil. \\ Shana Hastenpflug Wottrich ${ }^{2}$ \\ ¿Universidade Federal do Pampa, RS, Brasil. \\ Aline Cardoso Siqueira' \\ 'Universidade Federal de Santa Maria, RS, Brasil.
}

Resumo: Este estudo objetivou analisar as lembranças de infância e das práticas educativas de mães de crianças pré-escolares que usam práticas coercitivas ou indutivas na criação dos próprios filhos. Foram entrevistadas 12 mães, sendo que seis delas adotavam estratégias predominantemente indutivas (MPI) e seis, predominantemente coercitivas (MPC). A teoria fundamentada norteou a análise qualitativa. Entre os resultados, constatou-se que a infância das MPI foi caracterizada pelo predomínio do afeto e de eventos positivos e lúdicos. Ainda que algumas mães tenham sido alvo de ações coercitivas, elas relataram forte presença de práticas educativas indutivas. Por outro lado, as MPC relataram vivência de situações traumáticas, como alcoolismo, violência psicológica e sexual, associadas ao uso de punição física, ameaças e privação de afeto como estratégias disciplinares. Os dados sugerem a transmissão intergeracional das práticas educativas, caracterizadas pela forma como os pais educam, e as diversas estratégias que utilizam para orientar o comportamento dos filhos. Discute-se a implementação de programas de orientação parental que possam favorecer o uso de práticas educativas indutivas.

Palavras-chave: Práticas Educativas Maternas, Crianças Pré-Escolares, Intergeracionalidade, Relação Mãe-Filhos.

\section{Intergeracionality in the Context of Parenting Practices of Mothers of Preschoolers}

Abstract: This study aimed to analyze childhood memories and parenting practices of mothers of preschoolers with coercive or inductive parenting practices. The study was conducted with twelve mothers: six who used predominantly inductive discipline (PIM) and six predominantly coercive discipline (PCM). Qualitative analysis was guided by the Grounded-Theory. The results indicate that the childhood of predominantly inductive mothers was characterized by affection and positive and playful events. Although exposed to some coercive practices, they reported predominance of inductive parenting practices. Conversely, the childhood of predominantly coercive mothers was characterized by traumatic events such as alcohol abuse, sexual and psychological violence, physical punishment, threats, and lack of affection. Such findings suggest intergenerational transmission of parenting practices, observable through the way parents educate their children and the different strategies used to guide their behavior. In this scenario, this study discussed the implementation of parental guidance programs that may foment use of inductive parenting practices.

Keywords: Maternal Parenting Practices, Preschool Children. Intergenerationality, Mother-Children Relationship. 


\title{
Intergeneracionalidad en el Contexto de las Prácticas
}

\author{
Educativas de Madres de Niños Preescolares
}

\begin{abstract}
Resumen: Este estudio propone analizar los recuerdos de la infancia y de la creación de madres de niños preescolares que utilizan prácticas coercitivas o inductivas en la creación de sus propios hijos. De las 12 madres entrevistadas, seis madres adoptaban las estrategias predominantemente inductivas (MPI) y seis, las predominantemente coercitivas (MPC). La teoría fundamentada orientó el análisis cualitativo. Se constató que la infancia de las MPI fue caracterizada por el predominio del afecto y de las ocasiones positivas y lúdicas. Aunque algunas madres hayan sufrido acciones coercitivas, relataron fuerte presencia de las prácticas educativas inductivas. Por otro lado, las MPC relataron experiencias traumáticas, como alcoholismo, violencia psicológica y sexual asociadas al uso del castigo físico, de las amenazas y de la privación de afecto como estrategias disciplinarias. Los datos sugieren la transmisión intergeneracional de las prácticas educativas, caracterizadas por como los padres educan y las diversas estrategias que utilizan para orientar el comportamiento de sus hijos. Se discute la implementación de programas de entrenamiento parental que puedan favorecer el uso de prácticas educativas inductivas.
\end{abstract}

Palabras clave: Prácticas Educativas Maternas, Niños Preescolares, Intergeneracionalidad, Relación Madres-Niños.

A educação parental e o estabelecimento de limites é uma preocupação constante de muitos pais (Patias, Siqueira, \& Dias, 2012; Zanetti \& Gomes, 2014). É no ambiente familiar que a criança aprende regras e modos de se relacionar com o outro, sendo de fundamental importância atentar para as estratégias utilizadas pelos pais diante de determinados comportamentos dos filhos (Silveira \& Wagner, 2012).

Essas estratégias utilizadas pelos pais com o intuito de suprimir comportamentos considerados inadequados ou incentivar a ocorrência de comportamentos adequados (Alvarenga, Magalhães, \& Gomes, 2012) têm sido nomeadas como práticas educativas parentais (Alvarenga \& Piccinini, 2007; Hoffman, 1975, 1994). De acordo com Hoffman (1975, 1994), existem dois tipos de práticas educativas empregadas pelos pais na socialização e modificação do comportamento de seus filhos: as indutivas e as coercitivas. As práticas indutivas consistem em estratégias que estimulam a empatia e enfatizam as consequências negativas dos danos causados a outras pessoas. Dessa forma, buscam alterar o comportamento da criança por meio da descrição de regras e do uso de explicações acerca das consequências físicas e emocionais do seu comportamento para terceiros. Tais práticas auxiliam na internalização de valores morais, pois possibilitam que a criança compreenda os motivos que justificam a necessidade da mudança de comportamento (Hoffman, 1975, 1994). Em contrapartida, as práticas coercitivas consistem em estratégias que utilizam a aplicação direta da força e do poder dos pais, tais como punição física, privação de privilégios ou ameaças (Carmo \& Alvarenga, 2012; Hoffman, 1975). Estas estratégias fazem que a criança modifique seu comportamento por meio das reações punitivas dos pais e tendem a causar emoções intensas, como hostilidade, medo, raiva e ansiedade (Hoffman, 1975, 1994). A literatura aponta que práticas indutivas podem favorecer o desenvolvimento infantil, enquanto práticas coercitivas estão associadas a problemas de comportamento, especialmente em crianças em idade pré-escolar (Alvarenga et al., 2012; Marin, Piccinini, Gonçalves, \& Tudge, 2012).

Entende-se por idade pré-escolar o período dos três aos seis anos da criança (Papalia, Olds, \& Feldman, 2016). Nessa fase, a criança desenvolve a capacidade de regular seu comportamento e de fornecer aos outros informações sobre suas necessidades e interesses (Coll, Palacios, \& Marchesi, 1995). Os comportamentos agressivos e desafiadores também podem 
ser compreendidos como parte dessa fase do desenvolvimento e estão relacionados, por vezes, às frustrações do dia a dia (Papalia et al., 2006). Nesse contexto, o papel dos pais nesse período está relacionado não somente ao provimento da necessidade dos filhos, mas também auxiliá-los no entendimento de que nem todos seus desejos podem ser satisfeitos (Brazelton \& Sparrow, 2003). Especificamente com relação à idade das crianças associadas às práticas educativas parentais, Reppold, Pacheco, Bardgi, \& Hutz (2002) sinalizam que as estratégias educativas empregadas pelos pais se modificam à medida que a criança vai crescendo, sendo que, geralmente, essas estratégias consistem em explicações verbais, restrição de privilégios e estratégias punitivas.

O uso de punição física, ameaças e privação de privilégios pelos pais na tentativa de educar seus filhos pode representar risco ao desenvolvimento saudável da criança (Gershoff, 2013; Santini \& Williams, 2016). Pesquisas revelam associação entre ter sofrido castigos corporais na infância e aumento dos problemas de saúde mental na infância, adolescência e idade adulta, comportamentos agressivos, problemas de aprendizagem, atos infracionais e violência conjugal na fase adulta (Durrant \& Ensom, 2012; Gershoff \& Grogan-Kaylor, 2016). Ademais, estudos apontam uma relação entre ter sido educado por meio de punições físicas e a continuidade do uso dessas estratégias na vida adulta, quando os pais deparam com a tarefa de educar os próprios filhos, evidenciando a intergeracionalidade dessas práticas (Kerr, Capaldi, Pears, \& Owen, 2009; Madden et al., 2015; Marin et al., 2013; Ribeiro, 2012). Em estudo realizado por Dixon, Browne e Hamilton-Giachritsis (2009), os autores verificaram que as famílias em que pelo menos um dos pais tinha sofrido violência física na infância apresentavam quatro vezes mais chances de utilizar de práticas violentas na educação do próprio filho do que as famílias cujos pais não tinham histórico de violência.

Nesse contexto, diversos são os fatores descritos na literatura como determinantes nas práticas educativas parentais, tais como a idade da criança, o sexo, o temperamento, a ordem de nascimento e o número de filhos (Freitas \& Piccinini, 2010; Marin et al. 2013). Ainda, características relacionadas aos pais também podem influenciar nas práticas educativas utilizadas, destacando-se, nesse sentido, os aspectos intergeracionais das práticas, que dizem respeito à forma como eles foram educados pelos próprios pais
(Bem \& Wagner, 2006; Hoffman, 1975; Marin et al., 2013). A intergeracionalidade, com base na perspectiva teórica adotada como referência neste estudo, é entendida como a repetição ou não da forma como os pais foram educados na maneira como educam seus próprios filhos e consiste em um dos principais fatores mencionados como influente nas práticas educativas parentais (Falcke \& Wagner, 2005; Hennig, 2008; Shaffer, Burt, Obradovic, Herbers, \& Masten, 2009). As experiências que os pais tiveram em sua criação são lembradas e, por vezes, revividas quando eles se percebem diante do desafio de educar os filhos (Brazelton \& Sparrow, 2003), sendo que a continuidade ou descontinuidade do uso de determinadas práticas educativas está intimamente relacionada com a avaliação que os pais fazem acerca do modo como foram criados (Marin et al., 2013; Shaffer et al., 2009). Assim, o comportamento adotado pelos pais na educação dos filhos é permeado não somente pela experiência real com seus próprios pais, mas, principalmente, pela maneira como essa experiência foi elaborada emocionalmente $e$, consequentemente, é relembrada no momento em que, por sua vez, tornam-se pais e mães (Marin et al., 2013).

Apesar de a intergeracionalidade ser um fenômeno descrito por diversos pesquisadores, a transmissão entre as gerações de padrões aprendidos de comportamento não é um processo linear (Marin et al., 2013). Ainda que haja evidências de que, de fato, existe uma continuidade intergeracional no que diz respeito à parentalidade, o conhecimento sobre como se dá essa transmissão ainda é limitado (Neppl, Conger, Scaramella, \& Ontai, 2009), ao considerar que as experiências vivenciadas durante a própria infância em família não são, necessariamente, repetidas (Belsky, Conger, \& Capaldi, 2009). Os fatores que podem levar à descontinuidade das práticas educativas ainda não estão completamente esclarecidos, sendo necessário esforço da comunidade científica com fins de compreender tais aspectos. Dentre os fatores apresentados na literatura como influentes nessa descontinuidade, destacam-se a vivência de maior suporte social por parte dos pais, as experiências singulares de vida dos pais que os levam a uma reflexão sobre a maneira como foram educados e como gostariam de educar os filhos e os desencontros entre o casal conjugal acerca das estratégias educativas a serem adotadas (Hennig, 2008; Marin, 2009; Marin, Piccinini, \& Tudge, 2011; Villas Boas, 2013). 
Nesse contexto, é importante considerar a complexidade da intergeracionalidade no entendimento da adoção de práticas educativas indutivas ou coercitivas na educação dos filhos, já que as práticas podem ser mutáveis e fluidas, podendo ser alteradas ao longo do tempo, de acordo com o desenvolvimento da criança e dos seus pais (Dalla Porta, 2018; Marin, 2009). Desse modo, ao levar em consideração que a intergeracionalidade é um fator que parece exercer grande influência nas práticas educativas, esse estudo objetivou analisar as lembranças de infância e da criação de mães de crianças pré-escolares, de três a seis anos, que usam práticas coercitivas ou indutivas na criação dos próprios filhos.

\section{Método}

Este estudo é uma pesquisa de abordagem qualitativa, de caráter exploratório-descritivo e de corte transversal.

\section{Participantes}

Participaram deste estudo doze mães de crianças em idade pré-escolar, cujos filhos estavam matriculados em escolas públicas e privadas em uma cidade na zona urbana da região central do Rio Grande do Sul. Essas mães foram divididas em dois grupos, sendo que seis participantes pertenciam ao grupo das mães que utilizavam práticas parentais predominantemente indutivas (MPI) e seis mães pertenciam ao grupo de mães que utilizavam práticas parentais coercitivas (MPC). A realização do estudo com este número de participantes justifica-se a partir de um estudo realizado por Guest, Bunce e Johnson (2006), cujo objetivo foi estabelecer um número adequado de entrevistas no contexto da pesquisa qualitativa para atingir a saturação teórica dos dados em função do tema pesquisado. Os autores constataram que as primeiras doze entrevistas fornecem uma amplitude de temas que possibilitam a categorização, sendo que elementos básicos já estão presentes nas primeiras seis entrevistas.

No tocante à caracterização das participantes, a média de idade das MPI era de 42,8 anos, sendo que três tinham ensino superior completo e três, pósgraduação completa. No tocante à renda familiar, três MPI afirmaram receber entre três a seis salários mínimos, e três $\mathrm{MPI}$, mais de seis salários mínimos. Apenas uma MPI não estava trabalhando no momento da entrevista. Com relação ao número de filhos, três MPI tinham dois filhos e três tinham apenas um. Especificamente no que se refere ao sexo das crianças pré-escolares, quatro eram meninos e duas meninas. As MPC, por sua vez, tinham idade média de 31,8 anos, sendo que uma tinha ensino superior incompleto; uma, superior completo; uma, pós-graduação completa; uma, fundamental incompleto; uma, fundamental completo; e uma, ensino médio incompleto. Ainda, a renda familiar de uma MPC era de até um salário mínimo, duas recebiam entre dois a quatro salários mínimos e três, mais de seis salários mínimos. Das seis MPC entrevistadas, apenas duas trabalhavam. Com relação ao sexo das crianças, dois eram meninos e quatro, meninas. Três MPC afirmaram ter dois filhos, duas afirmaram ter três filhos e uma afirmou ter apenas um filho.

\section{Procedimentos}

Essa pesquisa faz parte de um projeto guardachuva intitulado "Práticas educativas e direitos da criança e do adolescente", aprovado pelo Comitê de Ética em pesquisa da instituição onde foi realizada e atende aos princípios éticos da pesquisa com seres humanos (registro $n^{\circ}$ 2.048.714), conforme a Resolução no 510/2016 do Conselho Nacional de Saúde. Tal projeto teve como objetivo conhecer as práticas educativas utilizadas por 56 mães de crianças em idade pré-escolar, de escolas públicas e privadas. $O$ recrutamento das participantes do projeto guardachuva ocorreu em duas escolas públicas e privadas de educação infantil, por meio do envio de bilhetes por intermédio dos professores, sendo que as mães que retornavam os bilhetes eram contatadas para o agendamento das entrevistas. Adicionalmente, algumas participantes foram acessadas a partir da divulgação do projeto de pesquisa nas redes sociais e de indicações. As participantes desse projeto responderam a uma ficha de dados sociodemográficos e uma entrevista semiestruturada sobre práticas parentais educativas. A ficha de dados continha questões relativas à idade da participante e de seu companheiro, escolaridade, profissão, estado civil, número de filhos e idade destes, número de pessoas residentes no domicilio familiar e pertença socioeconômica. Já a entrevista sobre práticas parentais educativas continha sete blocos de questões abertas que contemplavam situações vivenciadas pelas mães na educação dos filhos, como: hora da refeição, hora do banho, agressão a outras 
crianças, birras, uso da palmada, interferência de problemas externos no comportamento dos pais em relação aos filhos e lei da palmada.

Para a realização da pesquisa que originou este artigo, inicialmente foram acessadas as fichas de dados sociodemográficos das mães que participaram do projeto mais abrangente, sendo que, das 56 participantes do projeto guarda-chuva, 42 atendiam aos critérios de inclusão estabelecidos neste estudo (mães de crianças pré-escolares, com coabitação familiar e advindas de famílias nucleares). Após essa etapa, as respostas da entrevista semiestruturada sobre práticas educativas das 42 participantes selecionadas foram separadas e enviadas a dois pesquisadores com reconhecido conhecimento na área das práticas educativas parentais, para uma avaliação às cegas, com o intuito de que eles identificassem as mães que utilizavam práticas predominantemente indutivas ou predominantemente coercitivas. Desse modo, as 42 entrevistas foram enviadas pelas autoras desta pesquisa aos pesquisadores com conhecimento na área, juntamente com um quadro de códigos com itens que caracterizam as práticas como predominantemente indutivas ou coercitivas, com o intuito de definir os dois grupos de mães (indutivas e coercitivas). Por um lado, para que as mães fossem consideradas predominantemente indutivas, elas deveriam atender a, no mínimo, três dos quatro critérios estabelecidos por Hoffman (1975, 1994): 1) uso de explicações; 2) uso de acordos e negociações; 3) regras claras e consistentes; 4) limites por meio do diálogo. Por outro lado, as mães coercitivas deveriam atender a, no mínimo, três dos quatro critérios a seguir: 1) castigos e punição física; 2) uso de ameaças e chantagens; 3) privação de privilégios; 4) privação de afeto. Assim, os avaliadores externos definiram a presença dos indicativos de práticas coercitivas e as participantes com indicativos de práticas indutivas nas entrevistas semiestruturadas do projeto guarda-chuva. A partir dessa análise, o percentual de concordância entre os pesquisadores foi de $93 \%$.

Das 42 entrevistas analisadas, apenas 15 participantes atenderam a pelo menos três dos quatro critérios estabelecidos, sendo que, dessas, seis eram predominantemente indutivas e oito, coercitivas. As 15 participantes foram convidadas a participar da segunda etapa da pesquisa, as quais foram contatadas por telefone, considerando a ordem de inclusão no projeto guarda-chuva. A amostra foi comporta pelas primeiras seis participantes de cada grupo que aceitaram participar da segunda etapa do projeto. Todas as entrevistas foram gravadas em áudio, com o prévio consentimento das participantes e, posteriormente, transcritas para fins de análise.

\section{Instrumento}

Para a realização deste estudo, foram utilizados como instrumentos a ficha de dados sociodemográficos, oriunda do projeto guarda-chuva, e uma entrevista semiestruturada elaborada especificamente para o estudo. Essa entrevista semiestruturada continha questões relativas às lembranças da infância das mães e à forma como elas foram educadas, tais como: "Que lembranças você tem da sua infância?", "Como você foi educado(a)?", "Você poderia contar alguma situação que the marcou na sua educação?", "Que aspectos tu acreditas que interferem na maneira como tu educas teu filho?", entre outras.

\section{Análise dos dados}

Para a organização e análise dos dados, foi utilizado o modelo teórico da teoria fundamentada nos dados, que consiste em uma abordagem metodológica que tem como objetivo construir uma teoria com base nos dados sistematicamente coletados e analisados durante a pesquisa (Strauss \& Corbin, 2008). Os dados foram analisados a partir do processo de codificação, que envolveu três fases: codificação aberta, codificação axial e codificação seletiva. $O$ processo de codificação foi realizado a partir da utilização do software Atlas-ti 5.0. Para manter o sigilo e o anonimato, as participantes foram identificadas pela letra " $M$ ", seguido de um número que identifica a ordem de realização das entrevistas.

\section{Resultados e discussão}

A partir da análise dos dados, foram criadas duas categorias intituladas "Lembranças da própria infância", que se refere às lembranças positivas e negativas mencionadas pelas participantes na própria infância, e "Intergeracionalidade das práticas educativas vivenciadas na infância", que diz respeito à influência da maneira como as mães foram educadas na forma como educam os próprios filhos.

\section{Lembranças da própria infância}

Essa categoria abarca questões relativas às lembranças das MPC e MPI acerca da própria infância, 
como a relação com os pais e outras crianças, brincadeiras e situações marcantes. Enquanto os dois grupos de mães revelaram lembranças consideradas positivas, apenas o grupo de MPC mencionou ter vivenciado eventos considerados negativos durante a infância, como situações traumáticas vivenciadas no contexto familiar.

\section{Lembranças positivas}

Recordações consideradas positivas, principalmente em relação às lembranças de brincadeiras na infância e da convivência com outras crianças, foram mencionadas por cinco MPC (M2, M4, M6, M8, M11), conforme ilustra o relato a seguir: "Me lembro de brincadeiras, de andar de patins, bambolê, aquelas brincadeiras da minha geração, de brincar de boneca até os 13 anos de idade" (M4). Essa narrativa revela a importância atribuída pelas participantes aos momentos de interação, lazer e do brincar na infância. Sob essa perspectiva, Pessoa e Costa (2014) afirmam que as memórias de uma infância de brincadeiras com os irmãos e amigos representam uma parte da infância relembrada saudosamente por muitos pais, até mesmo por aqueles que carregam na memória lembranças difíceis relacionadas ao convívio e interação com os próprios pais na infância.

As MPI (M1, M3, M5, M9, M10, M12) também mencionaram as brincadeiras como parte das vivências positivas. "Eu brincava muito, brincava em casa, na casa dos meus amigos, brincava com brincadeiras de criança da época, nada de tecnologia" (M3). Nesse contexto, para muitas mães, a infância foi relembrada a partir das memórias de momentos de lazer e brincadeiras, sendo que, em alguns casos, surgem comparações acerca da própria infância com a do filho, no sentido de salientar as diferentes brincadeiras, o espaço físico e o desejo de que o filho vivencie algumas experiências da infância da mãe, fato que se coaduna com estudo de Wilbert (2009).

Ademais, cinco das seis MPI (M1, M3, M5, M9, M12) destacaram outras lembranças consideradas positivas na própria infância, como a presença de afeto e respeito na relação familiar: "Lembranças muito boas, criada com muito amor, carinho, coisas boas. De aprender a amar e a respeitar o próximo. Sempre fui educada com muito amor, muita conversa" (M1). Com base nas narrativas, percebe-se que as experiências e vivências das MPI na própria infância no contexto familiar são relembradas como boas e positivas, associadas aos momentos em família e à afetividade presente nas relações. Nessa perspectiva, relações de afeto e confiança na infância podem perpassar todo o ciclo vital. O afeto é um dos elementos essenciais nas relações humanas e consiste em um dos fatores que asseguram a continuidade do processo de desenvolvimento no decorrer das outras fases que compõem o ciclo da vida (Diniz \& Koller, 2010). Cabe ressaltar que as vivências positivas na própria infância tendem a refletir também de modo positivo na idade adulta e nas outras gerações (Belsky, Jaffee, Sligo, Woodward, \& Silva, 2005; Hennig, 2008). Estudo de Hennig (2008) corrobora esses achados ao constatar que a presença de memórias de relações afetivas na infância mostrou-se relacionada a práticas consideradas positivas, tais como supervisão parental e comportamento moral.

Com base nos dados das 12 entrevistas, foi possível verificar que tanto as MPC quanto as MPI vivenciaram situações consideradas positivas, que influenciaram seu desenvolvimento na infância, principalmente no que se refere a brincadeiras e momentos de lazer e diversão com outras crianças. Ainda, destaca-se que as MPI mencionaram lembranças positivas relacionadas às figuras parentais e à presença de afeto. Nesse sentido, essa subcategoria revela que momentos de lazer, diversão, trocas familiares, demonstração de afeto, respeito e cuidado, além de serem considerados positivos ao longo do desenvolvimento, podem atuar como fator de proteção, moderando as relações estabelecidas pelos indivíduos quando estes passam a exercer a função de mãe ou pai.

\section{Lembranças negativas}

As MPC (M2, M4, M7) destacaram memórias de momentos negativos e traumatizantes vivenciados nesse período, em decorrência de fatores de risco presentes no ambiente familiar, principalmente nas figuras parentais. A presença de conflitos familiares, brigas frequentes e alcoolismo na família evidenciou a vulnerabilidade no contexto familiar de uma das participantes: "Lembro-me do meu pai beber e eu odiar isso. Lembro-me de, eu, com nove anos, trancada no banheiro com mamãe, porque papai tinha chegado e tinha bebido" (M4). Tais lembranças revelam o quanto situações que expõem a criança à violência, psicológica ou física, impactam na infância e, consequentemente, no desenvolvimento da criança. A lembrança do uso de bebidas alcoólicas por ambos 
os pais, especialmente a mãe, também foi mencionada em estudo de Pinto e Colossi (2017) como parte da história familiar de mães de crianças com idade de três a seis anos que utilizavam práticas educativas coercitivas. O uso ou abuso de álcool e drogas, práticas educativas coercitivas e altos níveis de estresse são fatores parentais que podem consistir em um fator de risco para o desenvolvimento saudável dos filhos (Tremblay, Gervais, \& Petitclerc, 2008).

Uma lembrança traumática e de sofrimento foi mencionada por uma MPC, que foi vítima de abuso sexual pelo padrasto na infância. "A outra lembrança que eu tenho da minha infância que foi um momento muito ruim pra mim, foi quando o meu padrasto me abusou, acho que eu tinha quase oito anos quando ele fez isso" (M7). Este relato evidencia a fragilidade no ambiente familiar da participante, no qual o lugar onde deveria haver proteção contra qualquer tipo de violação de seus direitos foi onde a violência sexual ocorreu. As consequências do abuso sexual infantil não impactam somente a pessoa que foi vitimizada, mas também outras pessoas que podem ser afetadas secundariamente. Nessa perspectiva, pais que foram abusados sexualmente durante a infância parecem ter dificuldades em exercer a parentalidade, principalmente em relação à provisão de uma estrutura apropriada, disciplina consistente e expectativas comportamentais claras (Dilillo \& Damashek, 2003; Ruscio, 2001). Além disso, podem usar com maior frequência a punição física (Dilillo \& Damashek, 2003).

Algumas MPC, ainda, descreveram como um aspecto negativo a lembrança de falta de diálogo na família durante a própria infância, na qual os pais supunham que não era necessário conversar e explicar nada às crianças e consideravam que a criança não tinha o direito de manifestar opinião: "Lembro que eu perguntava pro meu pai e pra mãe 'porque eu não posso isso?', e eles diziam 'porque não, porque eu não quero'" (M2). Observa-se que a ausência do diálogo parece estar relacionada com o não reconhecimento da criança como um sujeito com opiniões, bem como com a compreensão dos pais de que o adulto ocupava uma posição de hierarquia, na qual a criança apenas ouvia e obedecia, fato também constatado em outros estudos (Kerr et al., 2009; Pinto \& Colossi, 2017; Villas Boas, 2013).

Com base nos resultados, essa subcategoria traz dados que enfatizam situações negativas provocadas, principalmente, pelas figuras parentais das MPC na própria infância. Essas situações, considerando a presença da violência em suas diversas formas de manifestação, podem influenciar não somente a interação entre pais e filhos, como também a forma como as pessoas vitimizadas estabelecem relações com outros ambientes. Assim, apesar da família ser considerada como o principal ambiente de socialização da criança, desempenhando importante papel no seu processo de desenvolvimento (Santini \& Williams, 2016), ela também pode representar um contexto de risco para sua integridade física e emocional.

\section{Intergeracionalidade das práticas} educativas vivenciadas na infância

Nessa categoria, serão descritas as diversas práticas utilizadas pelos pais das MPC e MPI com o intuito de educá-las na infância, bem como sua influência na forma como as participantes passaram a educar os próprios filhos. Destaca-se que tanto as MPI quanto as MPC mencionaram o dilema entre reproduzir as práticas utilizadas na própria educação ou utilizar estratégias diferentes na educação dos filhos.

\section{Mães predominantemente coercitivas}

As participantes classificadas como predominantemente coercitivas neste estudo, por utilizarem práticas como a punição física, ameaças e chantagens, privação de privilégio e de afeto na educação dos filhos, destacaram que essas foram algumas das diversas estratégias empregadas com elas, em sua infância, por seus próprios pais. Apesar das MPC relatarem algumas estratégias indutivas na própria educação, como o uso do diálogo no estabelecimento de regras, observam-se situações claras que evidenciam um histórico de práticas coercitivas em sua criação.

Nessa perspectiva, a presença de regras e do diálogo (M2, M6, M11) foram algumas das estratégias indutivas mencionadas. "A gente sempre foi criado com regras, e acho que isso é extremamente necessário, sempre sabendo o que é certo e errado" (M2). Essa narrativa evidencia uma avaliação positiva da participante quanto ao uso de estratégias que tinham como base o diálogo e as explicações, com o objetivo de introduzir valores importantes para suas vidas. Dados semelhantes foram encontrados em outros estudos (Belsky et al., 2005; Kerr et al., 2009), que enfatizam a presença de regras consistentes, supervisão parental, envolvimento entre pais e filhos e expressão de emoções positivas 
como características mencionadas na própria criação dos pais e consideradas positivas por eles.

Contudo, mesmo com a presença dessas estratégias indutivas, as mães (M2, M6, M7, M11) revelaram que práticas coercitivas também eram utilizadas com frequência na própria educação, como ameaças, chantagens e punições físicas. As chantagens e ameaças, de acordo com as participantes, estavam associadas geralmente com a perda de algum privilégio ou para sinalizar que punições mais severas poderiam ocorrer: "Ela dizia: 'na próxima, eu não vou falar mais, eu vou pegar a vara"' (M6). Percebe-se, assim, que as práticas educativas utilizadas por alguns familiares das participantes pretendiam interromper os comportamentos inadequados a partir do estímulo ao medo de alguma ação externa, como a interposição do pai, a perda de algum benefício ou a punição física (Hoffman, 1994; Villas Boas, 2013).

A punição física foi uma estratégia mencionada pela maioria das MPC (M2, M6, M7, M8, M11) como recorrente na própria educação. Assim, "dar laço" (expressão regional que significa usar punição física), "pegar a varinha" e "bater" foram expressões repetidas com frequência pelas participantes: "Quando a gente aprontava de não obedecer, daí tinha os castigos, a varinha de vez em quando, que até fez muito bem [risos]. Se não tivesse a varinha, a coisa tinha sido pior" (M2). Essa narrativa evidencia que algumas mães percebiam a punição física como necessária no contexto educativo, o que demonstra uma aceitação dessa estratégia, como já verificado em outros estudos (Patias et al., 2012; Ribeiro, 2012). Esses dados também remetem ao estudo de Gagné, Tourigny e Pouliot-Lapointe (2007), o qual ressalta que os pais, que foram educados por meio da punição física, acreditavam que essas estratégias não resultaram em danos e tendem a ser favoráveis a essa prática. Nessa perspectiva, a punição física ainda é considerada por muitos pais como uma estratégia com finalidade pedagógica, o que leva muitas pessoas que foram educadas a partir desse recurso a compreendê-lo como eficaz e reproduzir na educação de seus filhos (Donoso \& Ricas, 2011; Durrant \& Ensom, 2012; Gershoff \& Grogan-Kaylor, 2016; Marin et al., 2013).

Algumas MPC (M7, M8), ao relembrarem as práticas utilizadas na própria educação, avaliaram negativamente as situações em que a punição física era utilizada. "Eu me lembro de que, até os meus 10 anos de idade, eu fazia xixi na cama, era um problema, e todo santo dia eu apanhava por causa do xixi" (M7). Com base nesse relato, observa-se que, mesmo que a punição física vivenciada na infância seja avaliada negativamente, esta experiência parece influenciar na construção do próprio modelo de educação que, posteriormente, é estabelecido quando os filhos crescem e se tornam pais violentos (Gagné et al., 2007; Ribeiro, 2012).

Os dados mencionados anteriormente, levando-se em consideração se tratar de participantes que utilizam de práticas coercitivas na educação dos filhos, sugerem que um dos determinantes mais significativos para o uso de práticas educativas coercitivas na educação dos filhos pode ser o fato de que pais severos vivenciaram punição quando crianças, evidenciando o "ciclo da violência" (Madden et al., 2015, Marin et al., 2013; Pinto \& Colossi, 2017; Shaffer et al., 2009). Em outras palavras, a pessoa pode crescer naturalizando relações violentas e transmitindo o que aprendeu quando criança (Ribeiro, 2012). Assim, alguns autores (Hennig, 2008; Marin et al., 2013) apontam para a relação entre as memórias de cuidado na infância e as práticas educativas parentais, sendo que lembranças de rejeição, ameaças e punição física na própria criação podem estar associadas ao uso de punições inconsistentes nas práticas educativas direcionadas aos próprios filhos.

Nesse contexto, as participantes (M2, M4, M6, M7), ao avaliarem as práticas educativas presentes na própria infância e a forma como educavam os filhos, se percebiam recorrendo às mesmas práticas pelas quais foram educadas, evidenciando sua intergeracionalidade. Essas mães ressaltaram a dificuldade em não reproduzi-las, mesmo que elas estivessem cientes se que existem formas mais adequadas de educar um filho:

Principalmente essa coisa de briga de família, que hoje eu me vejo fazendo e eu dizia que essa era uma coisa que eu queria proteger delas não terem porque eu tive, mas ninguém consegue, porque você é reflexo do que viveu. Tento fazer diferente, mas, com certeza, me repito porque tem hora que sou, parece, o reflexo de minha mãe (M4).

À luz do exposto, alguns autores (Dixon et al., 2009; Kreppner, 2000; Madden et al., 2015; Marin et al., 2013) sinalizam a relação entre as práticas educativas e a intergeracionalidade, ao considerar que, mesmo que as mães avaliem negativamente o uso de determinados recursos educativos que foram empregados na sua própria educação, elas se percebem repetindo-os na educação de seus filhos. Esses dados também vão 
ao encontro dos resultados obtidos em pesquisa realizada por Hennig (2008), que destaca que as práticas parentais são influenciadas, de alguma forma, pelas memórias de cuidado na infância, sendo que algumas correlações foram identificadas no mesmo sentido (repetindo as mesmas estratégias) e outras no sentido oposto (modificando as estratégias).

Algumas MPC (M8, M10, M11) mencionaram o desejo de recorrer a práticas diferentes das quais foram educadas, justificando que buscavam não utilizar a punição física com tanta frequência. Apesar dessa tentativa de não repetir determinadas práticas educativas, as participantes relataram que, em algumas situações, recorriam à punição física, alternada com outras estratégias:

Busco fazer diferente, eu apanhei muito quando era pequena da minha mãe, então tento não fazer assim. Mas quando, vai, que tu fica [sic] num ponto que tu fala [sic], aí eu dou umas chinelada [sic]. Mas tento não fazer, porque aí, depois, quando cresce, diz 'ai porque eu, quando era pequeno, vivia apanhando da minha mãe'. Aí eu tento não seguir igual, sabe, tento mais conversar, deixar de castigo (M11).

Com base na narrativa apresentada, pode-se inferir que, por mais que algumas mães afirmem querer educar os filhos com estratégias diferentes das que foram educadas, principalmente em relação ao uso da punição física, essa estratégia ainda é presente no discurso das participantes, mesmo que elas justifiquem que esse recurso é utilizado com menor frequência. Isso sugere o quanto a punição física ainda é uma prática educativa compartilhada socialmente e culturalmente aceita (Patias et al., 2012). No mesmo sentido, os resultados da pesquisa realizada por Sagim (2008) destacam a dificuldade das mães em não perpetuarem a violência sofrida na própria criação, apesar de mencionarem não querer que os filhos tivessem a mesma infância, marcada pela presença da punição. Nesse contexto, as mães com histórico de violência apresentam dificuldades em responder de forma não violenta a determinados comportamentos dos filhos e parecem ser mais suscetíveis a reagir com punição física diante de comportamentos indesejados da criança (Bert, Guner, \& Lanzi, 2009).

Com alicerce nesses resultados, pode-se observar a intergeracionalidade das práticas educativas, o que reforça os resultados de estudos nacionais e internacionais que destacam a continuidade do uso de estratégias coercitivas na educação dos filhos (Dixon et al., 2009; Hennig, 2008; Kerr et al., 2009; Madden et al., 2015; Marin et al., 2013; Ribeiro, 2012). Dessa forma, romper com o ciclo da violência e agir de maneira diferente de como os próprios pais agiram na infância, pode exigir mais do que reconhecer a influência dos modelos passados na própria criação (Sagim, 2008).

Esta subcategoria, assim, destaca situações vivenciadas e relembradas pelas mães com relação à própria educação na infância, que evidenciaram o uso de práticas educativas coercitivas por seus pais. Nesse contexto, foram observadas opiniões distintas acerca dessas estratégias, sendo que, por vezes, as mães parecem avaliar os recursos utilizados como negativos e prejudiciais e, em alguns casos, as participantes, além de valorizar, acreditam que estratégias coercitivas utilizadas pelos pais foram determinantes na garantia de uma boa educação. Os dados dessa subcategoria evidenciam, desse modo, que a forma como as participantes foram educadas parece influenciar diretamente na maneira como elas educam e consideram adequado educar os próprios filhos, o que aponta para a continuidade do uso de práticas coercitivas e a consequente repetição de padrões de funcionamento parental apreendidos na infância.

\section{Mães predominantemente indutivas}

As MPI (que utilizavam estratégias como uso de explicações, regras claras e consistentes, limites por meio do diálogo e acordos e negociações para educar os filhos) mencionaram diversas práticas utilizadas por seus pais com o intuito de educá-las na infância, que podem ser caracterizadas como indutivas e coercitivas. Uma das principais estratégias mencionadas pelas seis MPI (M1, M3, M5, M8, M10, M12) como presente na própria criação é o uso do diálogo: “Na base da conversa bastante, mas sempre tive limites também. Sempre foi pela conversa" (M1). A presença de lembranças de práticas indutivas na própria educação pode consistir em um modelo parental que, posteriormente, as mães utilizam para educar os próprios filhos, consistindo em um fator que auxilia no emprego de práticas que favoreçam o desenvolvimento infantil (Böing, 2014; Kreppner, 2000; Marin et al. 2013). Experiências de uma educação baseada no afeto e diálogo tendem a estar relacionadas com um funcionamento familiar ligado a estilos parentais mais apropriados para 
o desenvolvimento saudável dos filhos (Böing, 2014). Assim, o uso de práticas parentais positivas pode favorecer, nos filhos, o desenvolvimento de características que, no futuro, podem contribuir para que eles também recorram a essas práticas na criação de seus próprios filhos (Kerr et al., 2009; Shaffer et al., 2009).

A maioria das MPI (M1, M3, M5, M10) mencionou a ausência de punição física na própria educação: "Na minha educação, nós nunca levamos um tapa, ninguém, nós éramos em seis" (M5). A ausência do uso de punição física pelos pais das participantes pode estar associada com a não aplicação da punição física como método educativo pelas participantes na educação dos próprios filhos, ao levar em consideração o modelo que tiveram durante a própria criação (Kreppner, 2000; Madden et al., 2015; Marin et al., 2013). Dados semelhantes foram encontrados em estudo de Hennig (2008), que verificou que a ausência de punição física na própria educação estava relacionada com a monitoria positiva na educação dos filhos e menor utilização de punição física como prática educativa.

Algumas MPI mencionaram a presença de práticas coercitivas em suas infâncias (M9, M12). Essas participantes destacaram o uso de gritos pelos pais com o intuito de sinalizar algum comportamento inadequado, evitar que eles ocorressem ou resolver algum conflito: "Mas era à base da briga, grito, sabe?" (M12). Ademais, essas mães relembraram episódios de punição física na própria educação, como a presença de palmadas e chineladas.

$\mathrm{Na}$ própria infância, houveram [sic] algumas práticas violentas, do tipo palmada e chinelada. Tanto que a gente brinca com a minha mãe até hoje: 'ah, tu era da pedagogia do Rider', que era um chinelo que ela tinha e que, quando dava a palmada com aquele chinelo, fica [sic] as bolinhas do Rider desenhada [sic] (M9).

Observa-se, a partir dos depoimentos, que tanto o uso de gritos como a punição física são estratégias avaliadas negativamente pelas $\mathrm{MPI}$, que marcaram tanto sua infância quanto a forma como elas compreendiam ser mais adequada de educar os filhos. Nesse sentido, o fato de as mães terem sido educadas por meio de práticas coercitivas, apesar de exercer forte influência, não garante que essas estratégias sejam avaliadas positivamente por elas e, consequentemente, empregadas na educação dos filhos (Belsky et al., 2009, Böing, 2014;
Kerr et al., 2009; Marin et al., 2013). Desse modo, a exposição a modelos de violência não implica necessariamente na maior aceitação da punição física (Gagné et al., 2007), o que pode ser percebido nessa subcategoria, tendo em vista que se trata de mães predominantemente indutivas. Ainda, destaca-se que, embora as pessoas educadas por meio da punição física sejam mais favoráveis à utilização dessa prática do que aquelas que não tiveram essa experiência, o fato de as mães sentirem-se ameaçadas ou humilhadas na sua infância pode fazer que elas discordem e avaliem negativamente o uso de estratégias coercitivas (Gagné et al., 2007). Essa constatação aponta para as diversas variáveis que podem explicar a transmissão ou não das práticas educativas parentais, dentre elas, a reflexão crítica que os pais fazem acerca da forma como foram educados (Marin et al., 2013).

À luz do exposto, ao levar em consideração a presença dessas estratégias de caráter coercitivo na infância e educação das MPI (M9, M12) e ao traçar uma relação entre a forma como elas foram educadas e, posteriormente, educam os próprios filhos, as participantes destacaram o desafio em não reproduzir modelos considerados inapropriados:

Tem essa coisa do que eu vejo que os meus pais fizeram errado e tento não reproduzir. Embora eu ache que a questão da reprodução, ela é tão mais forte que aquilo que justamente eu rechaço na minha educação, que é a questão do grito em momento de cansaço e estresse, é justamente o que eu me pego por vezes reproduzindo (M9).

Esse depoimento evidencia que a reprodução de práticas e comportamentos vivenciados na própria educação, por vezes, ocorre de maneira involuntária e vem acompanhada por uma reflexão autocrítica. Esse processo ocorre tendo em vista que, historicamente, as mães e os pais aprendem a cuidar dos filhos a partir do modelo adotado pelos seus próprios genitores ou cuidadores (Marin et al., 2013; Kreppner, 2000). Apesar dos desafios inerentes à tarefa de não reproduzir certas estratégias presentes na própria criação, todas as MPI afirmaram que avaliavam os aspectos que consideravam negativos na própria educação e, a partir disso, pensavam em outras estratégias mais adequadas, assim como reproduziam as estratégias que julgavam apropriadas:

A gente tem que ter a capacidade de fazer autocrítica, a minha educação foi assim, será que foi 
o melhor jeito? Aí tu vai [sic] pensar. Não, nesse aspecto foi o melhor jeito, então dá pra seguir. Em outro aspecto, tu pensa [sic] que dá pra ser diferente. Então, tu não vai te utilizar [sic] do exemplo como tu foi criado, e sim vai tentar melhorar aquilo a partir dessa autorreflexão (M3).

Especificamente com relação às estratégias que as MPI buscavam modificar, todas as participantes destacaram que tentavam evitar gritos e brigas, não aplicar punição física como estratégia educativa e participar mais da rotina dos filhos: "A minha mãe não era tão presente, eu quero estar presente, acho que a gente precisa saber o que está acontecendo" (M12). Por outro lado, dentre os aspectos da própria educação que algumas participantes (M1, M3, M9) buscavam transmitir, foram mencionados os valores passados durante a própria infância, como o de respeitar e amar ao próximo, ser responsável e solidário: "Acho que muito do que eu aprendi, e por acreditar em determinados valores que foram me passados. Como ter respeito ao outro, amor ao próximo, algumas coisas de personalidade e de caráter, a gente baseia isso" (M1). Pode-se perceber que as MPI parecem fazer uma avaliação e reflexão acerca da própria educação, com o intuito de modificar alguns aspectos que julgam inadequados e repetir padrões educativos aprendidos com os cuidadores da infância que consideram adequados.

As narrativas descritas evidenciam uma avaliação positiva das participantes acerca dos valores transmitidos pelos próprios pais e, consequentemente, uma tentativa das mães entrevistadas em disseminar tais valores na educação dos próprios filhos, aspectos também emergentes na pesquisa de Böing e Crepaldi (2016). O processo educativo, assim, tende a se alicerçar em determinados valores familiares que os pais e as mães internalizaram no decorrer de suas infâncias, os quais buscam transmitir aos filhos (Bem \& Wagner, 2006).

Com base nos dados apresentados, essa subcategoria evidencia a predominância do uso de estratégias consideradas indutivas na própria educação das MPI, o que parece ter exercido influência na forma como essas mães educavam os próprios filhos. Ademais, destaca-se a postura reflexiva das mães ao levar em consideração a manutenção de estratégias consideradas positivas e a extinção de estratégias presentes na própria criação que elas acreditavam não ser adequadas para o desenvolvimento saudável dos filhos.

\section{Considerações finais}

Socializar e favorecer o desenvolvimento de habilidades sociais e emocionais em crianças é um dos grandes desafios dos pais ou cuidadores. Nesse processo dinâmico, inúmeros fatores se tocam e se interligam, levando ou não à adoção de estratégias de educação eficazes e saudáveis. Os resultados desse estudo demonstraram que, nas mães investigadas, há diferenças e semelhanças entre o modo como foram educadas por seus pais e as estratégias utilizadas para educar seus próprios filhos.

As lembranças que as mães têm da própria infância consistem em um fator que pode influenciar na forma como elas educam os filhos, ao levar em consideração que estas vivências fizeram parte do seu desenvolvimento. Desse modo, algumas lembranças parecem ter impactado o desenvolvimento MPC e, consequentemente, a forma como elas se relacionam com os filhos, como a presença de vulnerabilidade no ambiente familiar e de práticas predominantemente coercitivas na própria educação.

Apesar da presença de algumas lembranças positivas na infância das mães predominantemente coercitivas e do uso de algumas estratégias de caráter indutivo em sua própria criação, as participantes destacaram situações de violência física, sexual e psicológica vivenciadas no ambiente familiar. Essas situações de violência experienciadas na infância tendem a constituir um fator de risco para o desenvolvimento, não somente para a constituição da pessoa, mas também para a forma como a pessoa que sofreu violência vai se relacionar com o mundo. Dito de outro modo, esses resultados sugerem que a violência vivenciada na família de origem destas participantes pode influenciar a forma como essas mães irão se relacionar com os próprios filhos, nas quais elas podem adotar práticas de caráter coercitivo, a exemplo do que vivenciaram na família, o que vai ao encontro da literatura nacional e internacional sobre o tema.

Já as mães predominantemente indutivas, apesar de algumas relatarem a presença de práticas coercitivas na própria criação, parecem ter vivenciado situações positivas, permeadas pelo afeto e diálogo com maior frequência. Tais lembranças foram mencionadas como parte dos aspectos que permeiam a forma como elas educam os filhos. Essas participantes destacaram a intenção de manter, na educação de seus filhos, as estratégias (consideradas positivas) utilizadas por seus pais na própria educação e de modificar 
as negativas. Nessa perspectiva, mesmo que as mães indutivas tenham relatado situações de punição física na própria educação, ao perceberem-se recorrendo a estratégias coercitivas com os filhos, apresentaram uma postura reflexiva e crítica na tentativa de buscar estratégias educativas que considerem mais apropriadas e eficazes.

Tais dados evidenciam o desafio e a complexidade inerente à tarefa de educar, que implica no emprego de uma diversidade de práticas. O esforço para a criação dos filhos em um ambiente sem violência é uma tarefa desafiadora, mas fundamental para a sociedade. Conhecer e utilizar práticas educativas parentais adequadas na educação dos filhos pode constituir um fator de proteção tanto para a criança em desenvolvimento quanto para as próximas gerações, pois é a partir das práticas educativas que as crianças irão construir modelos de se relacionar com a família e com terceiros, e educarão seus filhos no futuro.

Dentre as principais contribuições deste estudo, destacam-se as discussões empreendidas que permitiram compreender as especificidades que permeiam o uso de práticas indutivas ou coercitivas, com base nas vozes de mães de crianças pré-escolares. Desse modo, em termos de conteúdo, as reflexões construídas nesse trabalho contribuem para a ampliação do conhecimento acerca dessa temática, tendo em vista a escassez de estudos qualitativos na área. Ainda, este estudo contribui com a ampliação da literatura relativa às práticas educativas, principalmente no que se refere ao uso de práticas indutivas, ao levar em consideração que a maioria dos estudos encontrados estão direcionados para o uso de práticas coercitivas e os impactos destas no desenvolvimento da criança (Alvarenga et al., 2012; Durrant \& Ensom, 2012; Gershoff, 2016; Gershoff \& Grogan-Kaylor, 2016; Lee, Altschul, \& Gershoff, 2015; Marin et al., 2012; Patias et al., 2012; Ribeiro, 2012). Assim, considera-se fundamental que mais estudos que investiguem o uso de práticas educativas indutivas sejam realizados a fim de disseminar o conhecimento dessas estratégias não somente na comunidade acadêmica, como também para a sociedade em geral, colaborando para uma mudança nas práticas ainda tão arraigadas na sociedade.

Dentre as limitações deste estudo, ressalta-se que esta pesquisa esteve centrada em um grupo de mães residentes em uma região específica do país, que foram entrevistadas quando os filhos estavam em idade pré-escolar, compreendida pelo período de três a seis anos. Os resultados devem ser necessariamente compreendidos à luz desse contexto, considerando que mães com filhos em outra fase do desenvolvimento e de outras regiões poderão recorrer a outras práticas educativas. Ainda, este estudo foi realizado apenas com mães. Assim, sugere-se que os pais sejam investigados em pesquisas futuras. Ressalta-se também que estudos longitudinais qualitativos, realizados em diferentes contextos e em diferentes fases do desenvolvimento da criança, podem contribuir com o avanço do conhecimento, a fim de melhor compreender os aspectos que influenciam as mudanças e continuidades nas práticas educativas. Sugerem-se também estudos que busquem investigar as práticas educativas a partir das características da criança e dos pais, tendo em vista o modelo de influência recíproca.

Por fim, sinaliza-se a importância de programas e intervenções que busquem dar suporte aos pais e prevenir o uso de práticas coercitivas possibilitando que os pais conheçam estratégias educativas positivas. Os pais precisam ser apoiados e acolhidos em suas dúvidas sobre a tarefa de educar os filhos, podendo se beneficiar de programas de orientação parental voltados para a prevenção da violência. Acredita-se que, com base na conscientização acerca dos possíveis danos do uso da disciplina coercitiva, bem como da exposição de práticas mais saudáveis e positivas aos pais, é possível romper com o ciclo da violência e com os prejuízos que a disciplina coercitiva pode acarretar.

\section{Referências}

Alvarenga, P., Magalhães, M. O., \& Gomes, Q. S. (2012). Relações entre práticas educativas maternas e problemas de externalização em pré-escolares. Estudos de Psicologia, 29(1), 33-42. https://doi.org/10.1590/S0103-166X2012000100004

Alvarenga, P., \& Piccinini, C. A. (2007). O impacto do temperamento infantil, da responsividade e das práticas educativas maternas nos problemas de externalização e na competência social da criança. Psicologia: Reflexão e Crítica, 20(2), 314-323. https://doi.org/10.1590/S0102-79722007000200018

Belsky, J., Conger, R., \& Capaldi, D. M. (2009). The intergenerational transmission of parenting: Introduction to special section. Developmental Psychology, 45(5), 1201-1204. https://doi.org/10.1037/a0016245 
Belsky, J., Jaffee, S. R., Sligo, J., Woodward, L., \& Silva, P. A. (2005). Intergenerational transmission of warmsensitive stimulating parenting: A prospective study of mothers and fathers of 3-years-olds. Child Development, 76(2), 384-396. https://doi.org/10.1111/j.1467-8624.2005.00852.x

Bem, L. A., \& Wagner, A. (2006). Reflexões sobre a construção da parentalidade e o uso de estratégias educativas em famílias de baixo nível socioeconômico. Psicologia em Estudo, 11(1), 63-71. https://doi.org/10.1590/ S1413-73722006000100008

Bert, S. C., Guner, B. M., \& Lanzi, R. G. (2009). The influence of maternal history of abuse on parenting knowledge and behavior. Family Relations, 58(2), 176-187. https://doi.org/10.1111/j.1741-3729.2008.00545.x

Böing, E. (2014). Relações entre coparentalidade, funcionamento familiar e estilos parentais em uma perspectiva intergeracional [Tese de doutorado]. Universidade Federal de Santa Catarina.

Böing, E., \& Crepaldi, M. A. (2016). Relação pais e filhos: Compreendendo o interjogo das relações. Educar em Revista, 59, 17-33. https://doi.org/10.1590/0104-4060.44615

Brazelton, T., \& Sparrow, J. (2003). Três a seis anos: Momentos decisivos do desenvolvimento infantil. Artmed.

Carmo, P. H. B., \& Alvarenga, P. (2012). Práticas educativas coercitivas de mães de diferentes níveis socioeconômicos. Estudos de Psicologia, 17(2), 191-197.

Coll, C., Palacios, J., \& Marchesi, A. (1995). Desenvolvimento psicológico e educação: Psicologia evolutiva. Artes Médicas.

Dalla Porta, D. (2018). Práticas maternas na educação de pré-escolares [Dissertação de mestrado]. Universidade Federal de Santa Maria.

Dilillo D., \& Damashek A. (2003). Parenting characteristics of women reporting a history of childhood sexual abuse. Child Maltreatment, 8(4), 319-33. https://doi.org/10.1177/1077559503257104

Diniz, E., \& Koller, S. H. (2010). O afeto como um processo de desenvolvimento ecológico. Educar em Revista, 36, 65-76. https://doi.org/10.1590/S0104-40602010000100006

Dixon, L., Browne, K., \& Hamilton-Giachritsis, C. (2009). Patterns of risk and protective factors in the intergenerational cycle of maltreatment. Journal of Family Violence, 24(2), 111-122. https://doi.org/10.1007/s10896-008-9215-2

Donoso, M. T. V., \& Ricas, J. (2011). A prática do castigo físico em crianças na visão dos perpetradores. Revista de Enfermagem do Centro Oeste Mineiro, 1(2), 228-237. https://doi.org/10.19175/recom.v0i0.17

Durrant, J., \& Ensom, R. (2012). Physical punishment of children: Lessons from 20 years of research. Canadian Medical Association Journal, 184(12), 1373-1377. https://doi.org/10.1503/cmaj.101314

Falcke, D., \& Wagner, A. (2005). A dinâmica familiar e o fenômeno da transgeracionalidade: Definição de conceitos. In A. Wagner, Como se perpetua a família? A transmissão dos modelos familiares (pp. 25-46). EDIPUCRS.

Freitas, A. P. C. O., \& Piccinini, C. A. (2010). Práticas educativas parentais em relação ao filho único e ao primogênito. Estudos de Psicologia, 27(4), 515-528 https://doi.org/10.1590/S0103-166X20100004000097

Gagné, M., Tourigny, M., Joly, J., \& Pouliot-Lapointe, J. (2007). Predictors of adult attitudes toward corporal punishment of children. Journal of Interpersonal Violence, 22(10), 1284-1304. https://doi.org/10.1177/0886260507304550

Gershoff, E. T. (2013). Spanking and child development: We know enough now to stop hitting our children. Child Development Perspectives, 7(3), 133-137. https://doi.org/10.1111/cdep.12038

Gershoff, E. T. (2016). Should parents' physical punishment of children be considered a source of toxic stress that affects brain development? Family Relations, 65, 151-162. https://doi.org/10.1111/fare.12177

Gerfshoff, E. T., \& Grogan-Kaylor, A. (2016). Spanking and child outcomes: Old controversies and new meta-analyses. Journal of Family Psychology, 30(4), 453-469. https://doi.org/10.1037/fam0000191

Guest, G., Bunce, A., \& Johnson, L. (2006). How many interviews are enough? An experiment with data saturation and variability. Field Methods, 18(1), 59-82. https://doi.org/10.1177/1525822X05279903

Hennig, F. (2008). Relação entre práticas educativas parentais e memórias de cuidado na infância [Dissertação de mestrado]. Universidade Federal de Santa Catarina.

Hoffman, M. L. (1975). Moral internalization, parental power, and the nature of parent-child interaction. Developmental Psychology, 11(2), 228-239. https://doi.org/10.1037/h0076463 
Hoffman, M. L. (1994). Discipline and internalization. Developmental Psychology, 30(1), 26-28. https://doi. org/10.1037/0012-1649.30.1.26

Kerr, D. C. R., Capaldi, D. M., Pears, K. C., \& Owen, L. D. (2009). A prospective three generational study of fathers' constructive parenting: Influences from family of origin, adolescent adjustment, and offspring temperament. Developmental Psychology, 45(5), 1257-1275. https://doi.org/10.1037/a0015863

Kreppner, K. (2000). The child and the family: Interdependence in developmental pathways. Psicologia: Teoria e Pesquisa, 1(16), 11-22. https://doi.org/10.1590/S0102-37722000000100003

Lee, S. J., Altschul, I., \& Gershoff, E. T. (2015). Wait until your father gets home? Mother's and Fathers' spanking and development of child aggression. Children and Youth Services Review, 52, 158-166. https://doi.org/10.1016/j. childyouth.2014.11.006

Madden, V., Domoney, J., Aumayer, K., Sethna, V., Iles, J., Hubbard, I., Giannakakis, A., Psychogiou, L., Ramchandani, P. (2015). Intergenerational transmission of parenting: findings from a UK longitudinal study. European Journal of Public Health, 25(6), 1030-1035.https://doi.org/10.1093/eurpub/ckv093

Marin, A. H. (2009). Estabilidade e mudança nas práticas educativas maternas e paternas ao longo dos anos pré-escolares e sua relação com a competência social infantil [Tese de doutorado]. Universidade Federal do Rio Grande do Sul.

Marin, A. H., Piccinini, C. A., \& Tudge, J. R. H. (2011). Práticas educativas maternas e paternas aos 24 e aos 72 meses de vida da criança. Psicologia: Teoria e Pesquisa, 27(4), 419-427. https://doi.org/10.1590/S0102-377220110070400005

Marin, A. H., Piccinini, C. A., Gonçalves, T., \& Tudge, J. R. H. (2012). Parental child-rearing practices, behavior problems and pre-school children's social competence. Estudos de Psicologia, 17(1), 5-13. https://doi.org/10.1590/ S1413-294X2012000100002

Marin, A. H., Martins, G. D. F., Freitas, A. P., Silva, I. M., Lopes, R. C., \& Piccinini, C. A. (2013). Transmissão intergeracional de práticas educativas parentais: Evidências empíricas. Psicologia: Teoria e Pesquisa, $29(2), 123-132$. https://doi.org/10.1590/S0102-37722013000200001

Neppl, T. K., Conger, R. D., Scaramella, L. V., \& Ontai, L. L. (2009). Intergenerational continuity in parenting behavior: Mediating pathways and child effects. Developmental Psychology, 45(5), 1241-1256. https://doi.org/10.1590/ S0102-37722013000200001

Papalia, D. E., Olds, S. W., \& Feldman, R. D. (2006). Desenvolvimento humano (8a ed.). Artmed.

Patias, N. D., Siqueira, A. C., \& Dias, A. C. G. (2012). Bater não educa ninguém! Práticas educativas parentais coercitivas e suas repercussões no contexto escolar. Educação e Pesquisa, 38(4), 981-996. https://doi.org/10.1590/ S1517-97022012000400013

Pessoa, C. T., \& Costa F. M. L. (2014). Constituição da identidade infantil: Significações de mães por meio de narrativas. Psicologia Escolar e Educacional, 18(3), 501-509. https://doi.org/10.1590/2175-3539/2014/0183774

Pinto, L. A. P. A., \& Colossi, P. M. (2017). Percepção materna acerca das práticas educativas coercitivas e a transmissão de modelos familiares. Contextos Clínicos, 10(2), 157-171. https://doi.org/10.4013/ctc.2017.102.02

Reppold, C. T., Pacheco, J., Bardagi, M., \& Hutz, C. S. (2002). Prevenção de problemas de comportamento e o desenvolvimento de competências psicossociais em crianças e adolescentes: Uma análise das práticas educativas e dos estilos parentais. In C. S. Hutz (Org.), Situações de risco e vulnerabilidade na infância e adolescência: Aspectos teóricos e estratégias de intervenção. Casa do Psicólogo.

Resolução n510, de Conselho Nacional de Saúde. (2016). Resolução do Conselho Nacional de Saúde nº 510/16. http://conselho.saude.gov.br/resolucoes/2016/Reso510.pdf

Ribeiro, J. M. L. (2012). Uso da palmada como ferramenta pedagógica no contexto familiar: Mania de bater ou desconhecimento de outra estratégia de educação? Pesquisas e Práticas Psicossociais, 7(1), 52-58.

Ruscio, A. M. (2001). Predicting the child-rearing practices of mothers sexually abused in childhood. Child Abuse \& Neglect, 25(3), 369-387. https://doi.org/10.1016/S0145-2134(00)00252-0

Sagim, M. B. (2008). Violência doméstica observada e vivenciada por crianças e adolescentes no ambiente familiar [Tese de doutorado]. Universidade de São Paulo.

Santini, P. M., \& Williams, L. C. A. (2016). Parenting programs to prevent corporal punishment: A systematic review. Paidéia, 26(63), 121-129. https://doi.org/10.1590/1982-43272663201614 
Shaffer, A., Burt, K. B., Obradovic, J., Herbers, J. E., \& Masten, A. S. (2009). Intergenerational continuity in parenting quality: The mediating role of social competence. Developmental Psychology, 45(5), 1227-1240. https://doi. org/10.1037/a0015361

Silveira, L. M. O. B., \& Wagner, A. (2012). A importância das relações parentais frente aos problemas de comportamento na infância: Convergências teóricas. Interação em Psicologia, 15, 219-228. https://doi.org/10.5380/psi.v15i2.11002

Strauss, A., \& Corbin, J. (2008). Pesquisa qualitativa: Técnicas e procedimentos para o desenvolvimento da Teoria Fundamentada (2a ed.). Artmed.

Tremblay, R. E., Gervais, J., \& Petitclerc, A. (2008). Prévenir la violence par l'apprentissage à la petite enfance. Centre d'excellence pour le développement des jeunes enfants.

Villas Boas, A. C. V. B. (2013). Violência física contra a criança: Fatores de risco e proteção e padrões de interação na família [Tese de doutorado]. Universidade de Brasília.

Wilbert, D. D. (2009). Representações Sociais da infância e estilos de práticas educativas de mães e professoras de crianças de 0 a 6 anos de idade [Tese de doutorado]. Universidade Federal de Santa Catarina.

Zanetti, S. A. S., \& Gomes, I. C. (2014). Relação entre funções parentais e o comportamento de crianças pré-escolares. Boletim de Psicologia, 64(140), 1-20.

Daniele Dalla Porta

Psicóloga, Mestre em Psicologia pelo Programa de Pós-Graduação em Psicologia da Universidade Federal de Santa Maria, Santa Maria - RS. Brasil.

E-mail: danidallaporta@hotmail.com

(D) https://orcid.org/0000-0002-5751-4542

Shana Hastenpflug Wottrich

Psicóloga, doutora, docente da Universidade Federal do Pampa, Bagé - RS. Brasil.

E-mail: shana.wottrich@gmail.com

(D) https://orcid.org/0000-0003-0446-1982

Aline Cardoso Siqueira

Psicóloga, Doutora, Docente do Programa de Pós-Graduação da Universidade Federal de Santa Maria, Santa Maria - RS. Brasil.

E-mail: alinecsiq@gmail.com

(D) http://orcid.org/0000-0002-1432-0270

Endereço para envio de correspondência:

Universidade Federal de Santa Maria. Avenida Roraima, 100, prédio 74B, 2ªndar, sala 3205. Camoboi, Cidade

Universitária. Santa Maria - RS. Brasil.

Recebido 26/06/2018

Aceito 29/07/2019

Received 06/26/2018

Approved 07/29/2019

Recibido 26/06/2018

Aceptado 29/07/2019 
Psicologia: Ciência e Profissão 2021 v. 41 (n.spe 3), e205488, 1-16.

Como citar: Dalla Porta, D., Wottrich, S. H., \& Siqueira, A. C. (2021). Intergeracionalidade no contexto das práticas educativas de mães de crianças pré-escolares. Psicologia: Ciência e Profissão, 40 (n.spe 3), 1-16. https://doi. org/10.1590/1982-3703003205488

How to cite: Dalla Porta, D., Wottrich, S. H., \& Siqueira, A. C. (2021). Intergeracionality in the context of parenting practices of mothers of preschoolers. Psicologia: Ciência e Profissão, 40 (n.spe 3), 1-16. https://doi. org/10.1590/1982-3703003205488

Cómo citar: Dalla Porta, D., Wottrich, S. H., \& Siqueira, A. C. (2021). Intergeracionalidad en el contexto de las prácticas educativas de madres de niños preescolares. Psicologia: Ciência e Profissão, 40 (n.spe 3), 1-16. https://doi. org/10.1590/1982-3703003205488 